\title{
Masacres, genocidio y acompañamiento en Guatemala: una experiencia personal ${ }^{*}$
}

\author{
RICARDO FALLA**
}

\section{Cómo me involucré con el tema del genocidio}

¿ Cómo me topé con él? Ustedes pueden preguntarse también, ¿cómo me topé con la violación de mujeres? ¿cómo llegué a ponerme en contacto con el tema de los desaparecidos y desarraigados? ¿Cómo, si nosotros o nosotras no somos desarraigados, ni tal vez hemos sufrido violencia femenina, ni hemos estado en las fauces del genocidio...?

Voy a comenzar desde el principio, involucrándome en el relato. Yo soy antropólogo. No soy jurista. Tal vez por eso pueden salir afirmaciones no muy ortodoxas de mi boca. Estudié antropología en la Universidad de Texas en los años sesenta. Hice mi tesis doctoral sobre temas de cambio religioso, siguiendo la teoría (no la religiosa) de Richard N. Adams, amigo de su entusiasta seguidor, el "Flaco" (Roberto) Varela.

El tema fue surgiendo de mi identidad principal, como jesuita. Compañeros de mi orden religiosa y el contacto con el pueblo indígena me llevaron a una radicalización cada vez mayor. Estamos hablando de la década de los setenta. Luego, en 1980 estalló en Guatemala la persecución contra los sacerdotes, es decir, empezaron a matar curas, pero yo ya estaba en Nicaragua, apoyando como antropólogo desde la investigación al proceso revolucionario sandinista de la Reforma Agraria. Fue entonces cuando allí, en Nicaragua, surgió entre amigos el plan para volver de manera clandestina a Guatemala a una zona liberada. Para eso, nos fuimos a entrenar a Cuba, supuesta- mente en autodefensa. Recuerdo, cuando Ríos Montt estaba dando el golpe de Estado el 24 de marzo de 1982 en Guatemala, nosotros estábamos tomando en Managua el avión de Cubana para volar a La Habana. Allí estaríamos tres meses con otros compañeros y al volver de nuevo a Managua nos encontramos que era ya imposible la entrada clandestina a Guatemala, pues las grandes masacres habían desestabilizado a la organización guerrillera Ejército Guerrillero de los Pobres (EGP), la que debía hacer posible nuestra entrada desde Chiapas. Quedamos parqueados en Managua.

Entonces, unos jesuitas vinculados a esa organización revolucionaria me aconsejaron volar a México para constatar de primera mano, desde Chiapas y a través de los refugiados, lo que estaba sucediendo en Guatemala. Así fue cómo, en compañía de algunas personas de la Diócesis de San Cristóbal, hicimos una gira fronteriza por los campamentos de refugiados. Ya por Tziscao, a escasos metros de la frontera guatemalteca, empezamos a oír de una masacre tremenda. Poco antes le habían informado de ella a don Samuel Ruiz en el ejido de Cuauhtémoc. Estaba vivo el último testigo de la masacre en el ejido de Santa Marta, cerca de la Laguna Brava. Él "había salido de entre los muertos", nos solían repetir y repetir según nos acercábamos a su lugar. La masacre había sucedido el 17 de julio de 1982. Nosotros, dos meses después, a principios de septiembre, estábamos por fin, después de haberlo ido buscando, frente a ese hombre excepcional, don Mateo Ramos Paiz, que al anochecer había escapado del cerco del ejército.

\footnotetext{
* Este texto corresponde a la conferencia magistral impartida la mañana del 25 de febrero de 2020 en la sala Cuicacalli de la Universidad Autónoma Metropolitana-Iztapalapa, Ciudad de México.

** Antropólogo guatemalteco y sacerdote jesuita. Guatemala.
} 
En una escuela del ejido nos relató la historia. Lo rodeaban alrededor de 15 hombres que habían escapado del ejército, pues habían quedado fuera del cerco militar. Yo tuve la oportunidad de grabar su relato y guardarlo hasta este momento. Era ya de noche y antes de despedirnos le pedí si podían escribir los nombres de las víctimas y, en efecto, al día siguiente, temprano de mañana, un secretario joven estaba pegado a una mesa sacando lo que entonces llegó a ser una lista de 302 nombres. Ya con la lista, tuvimos una misa con la compañía de un sacerdote de la diócesis y una religiosa, y leímos uno por uno todos los nombres. Sólo oímos un murmullo de los parientes de otra comunidad vecina que se habían salvado. Pero allí me di cuenta de que había muchos nombres repetidos por la costumbre del k'axel (sustituto) en esos pueblos mayas y les pedí que para desambiguarlos se juntaran los testigos de nuevo y dieran la edad y el parentesco de cada uno.

Años después, al hacer el libro Negreaba de zopilotes (Falla, 2011), completé esa lista con otras tres de fuentes distintas y dio el total de 376 personas fríamente masacradas en un solo día: ancianos y ancianas, mujeres y hombres trabajadores, niños de todas las edades. Don Mateo insistía que eran inocentes, es decir, no eran guerrilleros. Por eso, junto a "hombres" escribían en la lista "trabajadores", es decir, civiles, cuyo trabajo no es la guerra.

\section{Masacre de San Francisco, Nentón (17 de julio de 1982)}

Pero ¿qué fue lo que don Mateo me contó? Bajo ahora a lo muy concreto, animado por lo que nos decían los maestros y maestras de la antropología, como Clifford Geertz. Afirmaban: hay que partir de un evento culturalmente denso para analizarlo y subir poco a poco a las generalizaciones.

Lo haré así, deteniéndome en pausas para tocar puntos de la definición de genocidio, acercándome como antropólogo al jurista o al profesional de los derechos humanos. Dos disciplinas distintas, eso hay que defenderlo, pero emparentadas o, si quieren, enamoradas. Ojalá.

Pero antes de oír a don Mateo, permítanme brevemente hacer la "composición del lugar". ${ }^{1}$ San Francisco era una finca de ganado propiedad de un coronel. Tenía una ranchería como de 50 casas, ubicadas alrededor de una pirámide maya, quizá ch’ol, que todavía queda, junto a un gran árbol. Allí, como en el centro del lugar, había dos casas principales de uso de la comunidad ranchera, un oratorio católico, no había evangélicos en el lugar, y una alcaldía auxiliar. La población era de habla chuj, procedente de San Mateo Ixtatán, un pueblo de la cordillera de los Cuchumatanes.

La aldeíta con la pirámide se encontraba (o se encuentra, porque la pirámide está allí) en las estribaciones de la sierra de los Cuchumatanes, por donde bajan ríos pequeños que a veces salen de las entrañas de la montaña. Distaba de la frontera mexicana dos o tres horas a pie. Las ondulantes montañas cuando llegan a la frontera se aplanan y comienzan los valles. Esa zona fronteriza tiene muchas concentraciones de agua, como la Laguna Brava, azulísima, u otras como pequeños ojos que ven al cielo... cuando está despejado, porque llueve bastante. Más cerca de la frontera existía una comunidad hermana, llamada Yulaurel, como a $45 \mathrm{mi}$ nutos de la línea, que era propiedad colectiva de sus residentes y de los que residían en San Francisco. Ellos sobrevivieron y escaparon a México el día de la masacre. Volvamos a don Mateo, e iremos haciendo las pausas de reflexión.

Nos contó que el sábado 17 de julio de 1982 llegaron a San Francisco como 400 soldados acompañados de un helicóptero.

Pausa: claramente se trata del ejército, no de la guerrilla, como agente de la masacre. En ese tiempo, el ejército culpaba a la guerrilla de haber sido la causante de las masacres. En este caso, no podía serlo. La guerrilla no tenía helicópteros. Además, se supo del recorrido exacto de la infantería antes de llegar a San Francisco. Había salido de la cabecera municipal de San Mateo Ixtatán y había pasado por lugares donde después averiguamos que también habían cometido masacres semejantes, aunque no tan numerosas. Por ejemplo, en las aldeas chuj de Sebep y Patalcal.

Prosigue don Mateo: lo primero que hacen es circular la ranchería de la finca, para que nadie salga del cerco de las 50 casas, ni entre a él.

Pausa: se trata de un cerco militar. Nadie salga. Nadie. Nadie entre. Nadie. Luego se confirmará que es para matar a todos. Ni se escape la gente de la aldea, ni entren posibles guerrilleros a liberarlos. Ya está prefigurado el carácter genocida de la masacre. Masacre total. Sólo quedan fuera los que estaban sembrando. Son los sobrevivientes. Tal vez como 18.

Prosigue don Mateo: luego dividen a la gente en dos, los hombres son encerrados en la alcaldía auxiliar,

\footnotetext{
1 Término usado por Ignacio de Loyola en sus Ejercicios espirituales para situar en la escena a quien los sigue, como si estuviera presente.
} 
una casa pequeña de tejamanil, y las mujeres con los niños en la iglesita católica.

Pausa: todo el operativo sigue un protocolo preestablecido que se repite, con sus adaptaciones, en muchas otras masacres, lo cual indica que hay una intencionalidad, que no parte de los soldados ni del capitán que coordina el operativo, sino que se origina más arriba. Es decir, lo que se va a desarrollar no es un estallido espontáneo de furia de los soldados, ni tampoco un fuego cruzado, sino algo fríamente calculado. Con más documentación, luego se podrá comprobar que esa intencionalidad no responde a móviles únicamente de un acto, sino a toda una política y una estrategia contrainsurgente.

Prosigue don Mateo: ya encerrados los dos grupos, comienzan los soldados con las mujeres. Las rafaguean y ellas gritan, pero no mueren todas. Don Mateo que está encerrado en la alcaldía auxiliar oye los gritos y allí se le comienza a develar lo que sucederá, pero que no creía que pasaría. Las llevan a las casas por grupitos de soldados, donde después las violan y las matan. “¿Cómo sabe usted eso, le pregunté, si usted estaba encerrado?". "A los diez días volvimos y las encontramos con sus cortes levantados, medio quemadas." Después de matarlas o todavía vivas, eso no lo precisa don Mateo, les habían quemado las casas encima.

Pausa: de todas estas masacres la violación sexual era una parte casi diríamos esencial, no sólo para pagar a los soldados por su trabajo, ni para causar terror en la población, que ya no habría que controlar porque moriría; como un exceso de animalidad desenfrenada, lo típico de la emoción combinada de racismo y de dominación del hombre sobre la mujer, que rompe los moldes de la lógica, pero que debe estar calculado y promovido en el protocolo de la intencionalidad política.

Sigue don Mateo: después, todo por pasos, van a los niños que quedaron en la iglesia. Los sacan y los matan. "Lo vimos, dice el testigo, a través de una rendija de una ventana". El soldado saca arrullando al bebé y le mete el cuchillo. Les salen las tripas y, como grita, lo agarra de un piecito y le estalla la cabeza contra un palo. Y luego tira el cuerpecito, como si fuera el de un animal ya muerto. "Pero, ¿qué hicieron los niños?", dice don Mateo, "si eran inocentes; ni que fueran animales". Animales, no el niñito, sino animales los soldados que tratan como animales a las gentes.

Pausa: si, hablando de estas faltas incomprensibles de inhumanidad, se puede hablar de más y de menos, creo que esto es lo más claro del carácter genocida de la masacre. Este acto corresponde a lo que los oficiales decían al arengar (en Huehuetenango) a los hombres para que no apoyaran a la guerrilla. "Si no dejan a sus padres, es decir a la guerrilla, decían, los mataremos hasta la semilla”. Hasta la semilla. Para que nunca más nazca este pueblo. Los niños, vistos como la semilla del pueblo. Esto es genocidio, representado con lo más necesario y querido de esta gente maya, el maíz... y sus hijitos e hijitas.

La gente de estos pueblos ordinariamente no sabe qué es genocidio, desconoce la definición complicada y resbalosa. Pero sí se da cuenta del salvajismo que hay detrás de este acto de matar niños. Como los nazis que los tiraban al aire y allí en el aire les disparaban como pelotas de juego.

Prosigue don Mateo: después descansaron y comieron de dos novillos que habían ido a buscar, no pertenecientes al dueño de la finca, sino de los rancheros.

Pausa: la masacre es trabajo, de nuevo, planificado. Trabajo que necesita cierto número de soldados para ejecutarlo. Trabajo que exige descanso. Razón para que se haga en poblaciones pequeñas, escogidas. En este caso entre 300 o 400 soldados podían hacer el trabajo de la masacre de 50 casas en un día. Si la población era mayor o necesitaban más elementos o más días.

Y los novillos nos llevan a una corta digresión a favor de la autonomía relativa de las ciencias sociales. San Francisco era una finca de ganado y la guerrilla se aprovisionaba de ella con la consecuencia del ladronismo. Existía sin duda una relación de la gente con ella, pero don Mateo no lo cuenta. Al defender los derechos humanos yo he encontrado, incluso en mí mismo, esa actitud de invisibilizar la parte activa de las víctimas, como si esa parte oscureciera su inocencia. En el testigo se comprende, porque por esa relación los matan. En los defensores de derechos humanos, tal vez porque la parte activa (“¿en qué estaban metidos?”) debilita de hecho la prueba. La consecuencia es que las ciencias sociales resulten maniatadas y al pueblo se le oscurezca parte importante de su memoria, donde está una gran fuerza para el futuro. Exagerando, sólo se ve una cara de la luna, no la luna entera. Ojo, la luna es mentirosa, nunca muestra lo que hay detrás.

Prosigue don Mateo: después, van con los hombres. Los sacan de la alcaldía auxiliar y los van matando con bala o machete. Cuenta don Mateo que había un hombre ya muerto y el capitán (Castillo-don Mateo no le sabe el nombre-) se le abalanza y le saca el corazón. “¿Y qué hizo con él? -le pregunta el antropólogo-, ¿lo mordió?". "A saber, dice, no quise ver y me senté y agaché la cabeza".

Pausa: era un comportamiento ritual. Sabemos también que tomaban sangre humana. Era para darse fuerza, para darle fuerza a la tropa, porque había 
soldados que flaqueaban. ¿Cómo puede concebirse que la comunión del corazón de ese pueblo odiado que quieren que desaparezca hasta la semilla les dé fuerza? En ese sacrificio y comunión parece que se prefiguraba el nacimiento de una Patria Nueva, cuyo nervio era ese ejército kaibilizado (conformado a imagen del soldado de la contrainsurgencia por excelencia, llamado kaibil). ${ }^{2}$

Prosigue don Mateo: cuando ya todos están muertos y ya anochece, apilan los cadáveres de los hombres en la alcaldía auxiliar y don Mateo, que está vivo, queda debajo de ellos. Entonces, piensa (víctima activa), mientras los oye tocar las guitarras y las grabadoras robadas, y dice lo que estaba pensando, "Hasta aquí estoy vivo. Pero, ¿qué tal si le prenden fuego a esta casa?”. Se zafa de los muertos y se hinca ante ellos y les pide: "Ustedes ya están libres, iiidéjenme a mí ir en libertad!!!”. Siente fuerza, se para y se quita las botas para no hacer ruido al saltar. Abre la ventana y escapa "arrastrándose como culebra". Camina hacia México. En la mañana camina. El estúpido antropólogo le pregunta: “¿Va usted triste, don Mateo?” Ha perdido a todos los suyos. Pero don Mateo sorpresivamente le contesta, "No, no voy triste. Voy como bolo. No sé si es de día o es de noche. No llevo sombrero. No he comido nada. Voy como si hubiera destazado un animal".

Pausa para reflexionar y sentir. La pausa debería ser larga. Para sentir: es el hombre de la noche oscura. Tal vez decir esto es dar una mirada espiritual del genocidio. Más todavía, es la cumbre de la masacre, aunque parezca paradójico. La vida ha vencido a la muerte. Hay una luz de esperanza frente al genocidio. Sólo esperanza, no evidencia, tratarlo como evidencia sería peligroso, como si siempre habrá supervivencia del genocidio.

Y por eso -no sé si aquí hay influjos de mi fe-este hombre trae al mundo una buena noticia. ¿Cuál es esa ¡buena! noticia? Es que dice, “¡Estoy vivo! Vencí el poder de la muerte, el poder del Estado y del capital (las clases dominantes apoyaban el genocidio). Lo puedo contar. Estoy vivo".

Trágicamente a este hombre lo mataron en el refugio, confundido por "brujo", pues tenía poderes especiales de curación. Hasta los oficiales de la migración mexicana llegaban a consultarlo. Visité su tumba, sin lápida, ni nada, algo tristísimo, en un cementerito de la Finca San Pedro que la Diócesis había comprado para los refugiados cerca del ejido de Santa Marta.

\section{Otras masacres genocidas}

Dejamos a don Mateo y miramos esta lista de masacres con nombres desconocidos, tal vez, pero que señalan puntualmente la estrategia del ejército de destruir los núcleos que eran base de la población indígena (véase cuadro 1).

La principal conclusión para el tema del genocidio es que fueron todas, excepto una, contra el pueblo indígena de Guatemala. Por ende, son reflejo del racismo y de la discriminación étnica estructural del Estado. Si se contraargumenta: "no, son sólo reflejo del área donde había insurgencia”, respondemos, “¿por qué había insurgencia allí?" De nuevo caemos en la constatación del racismo estructural de la sociedad y del Estado que la respalda. Son áreas donde hubo un levantamiento, entre otras razones, por el ansia de liberación de esa discriminación.

No en todas las aldeas o parajes el ejército mató a todas las personas. Yo sólo conozco en detalle además de la de San Francisco, las tres masacres del Ixcán. En la de Piedras Blancas intentó matar a toda la comunidad, aunque siempre hubo algún sobreviviente que escapó. En la de Cuarto Pueblo, masacre grande, mató a todas las personas que quedaron en el cerco del centro de la aldea; pero no pudo dirigirse a todas las personas que quedaron en las casas, distantes y dispersas que no se acercaron al mercado dominical. Pero en la tercera, la de Xalbal, el ejército fue matando casa por casa, en cadena, no al grupo cercado. La comunidad se había ya dispersado. No la pudo cercar. Estos hechos nos hacen pensar en la definición de genocidio. La destrucción del grupo no tiene que ser total para darse el genocidio. Puede haber una intención de totalidad, pero su realización ser imposible, entonces la destrucción es parcial.

Los números indican que no hubo una sola masacre mayor de 400 víctimas. Se centró en poblaciones pequeñas, aldeas no muy grandes o parajes. Si hubo una masacre numerosa en el centro municipal (Rabinal o San Mateo Ixtatán), ésta fue parcial. Esta forma de proceder del ejército nos hace ver que su estrategia iba contra los centros neurálgicos del pueblo indígena. ¿De dónde se inspiró el ejército para diseñarla? Probablemente, al menos en parte, fue una estrategia espejo de la inserción (no infiltración) guerrillera: trabajar esos lugares como puntos sólidos de los resortes del levantamiento y de la organización. ${ }^{3}$

\footnotetext{
2 Véase ampliamente Vela Castañeda (2014).

3 Buena lección para la organización popular, y para nosotros profesionales de la antropología, que a veces nos reducimos a visitas de médico.
} 
Cuadro 1

Lista de algunas grandes masacres de Guatemala*

\begin{tabular}{|c|c|c|c|c|c|c|}
\hline Fecha & Comunidad & Municipio & Departamento & Número & Etnia & Agente \\
\hline 1981-05-31 & S. Mateo Ixtatán & S. Mateo Ixtatán & Huehue & 55 & Chuj & Ejército \\
\hline 1982-01-02 & Pichec & Rabinal & Baja Verapaz & 32 & Achí & Ejército \\
\hline $1982-02-13$ & Chisis & Cotzal & El Quiché & 132 & Ixil & Ejército \\
\hline 1982-03-13 & Río Negro & Rabinal & Baja Verapaz & 177 & Achí & Ejército \\
\hline 1982-03-14 & Cuarto Pueblo & Ixcán & El Quiché & 350 & Multiling & Ejército \\
\hline 1982-03-16 & S. Ant. Sinaché & Zacualpa & El Quiché & 108 & Kiché & Ejército \\
\hline 1982-03-19 & Estanzuela & Joyabaj & El Quiché & 57 & Kiché & Ejército \\
\hline 1982-03-19 & Arriquín & Zacualpa & El Quiché & 83 & Kiché & Ejército \\
\hline 1982-03-23 & La Estrella & Chajul & El Quiché & 96 & Ixil / Kanjob & Ejército \\
\hline 1982-04-01 & Xalbal & Ixcán & El Quiché & 38 & Multiling & Ejército \\
\hline 1982-04-03 & Chel & Chajul & El Quiché & 90 & Ixil & Ejército \\
\hline 1982-05-14 & Los Encuentros & Rabinal & Baja Verapaz & 94 & Achí & Ejército \\
\hline 1982-05-18 & Piedras Blancas & Ixcán & El Quiché & 55 & Mam & Ejército \\
\hline 1982-05-18 & S. Ant. Sinaché & Zacualpa & El Quiché & 51 & Kiché & Ejército \\
\hline 1982-05-30 & S. Ant. Sinaché & Zacualpa & El Quiché & 40 & Kiché & Ejército \\
\hline 1982-06-12 & Chacalté & Chajul & El Quiché & 55 & Ixil & Guerrilla \\
\hline 1982-07-07 & Puente Alto & Barillas & Huehue & 353 & Kanjob & Ejército \\
\hline 1982-07-13 & Sebep & S. Mateo Ixtatán & Huehue & 60 & Chuj & Ejército \\
\hline 1982-07-14 & Petenac & S. Mateo Ixtatán & Huehue & 86 & Chuj & Ejército \\
\hline 1982-07-17 & S. Francisco & Nentón & Huehue & 376 & Chuj & Ejército \\
\hline $1982-07-17$ & Plan de Sánchez & Rabinal & Baja Verapaz & 268 & Achí & Ejército \\
\hline 1982-09-11 & Lancetillo & Uspantán & El Quiché & 26 & Kekchí & Ejército \\
\hline 1982-09-14 & Agua Fría & Uspantán & El Quiché & 92 & Achí/Kiché & Ejército y PAC ${ }^{* *}$ \\
\hline $1982-11-15$ & Parraxtut & Sacapulas & El Quiché & 27 & Kiché & Ejército \\
\hline $1982-12-04$ & Bacanal & Rabinal & Baja Verapaz & 58 & Achí & Ejército \\
\hline 1982-12-07 & Dos Erres & La Libertad & Petén & 190 & Mestiza & eEjército \\
\hline
\end{tabular}

* No es una lista exhaustiva. Según el recuento de la Comisión para el Esclarecimiento Histórico (CEH) fueron 626 (Comisión para el Esclarecimiento Histórico, 1999: 86).

** Patrullas de Autodefensa Civil.

Sobre "la etnia": para ser exacto, se trata del idioma, como señal distintiva de la etnia. Aquí puede haber todo un debate sobre la delimitación en concreto de la identidad étnica. Creo que no es un problema teórico, sino de la realidad. El idioma llega a ser una señal diacrítica de la identidad cuando hay convivencia de personas de muchas lenguas en un lugar, como en las comunidades multilingües. Pero, en el concepto de genocidio se refiere a la etnia según la percibe el agresor.

En la lista aparece una comunidad "mestiza", esto es, de personas provenientes de población no indígena asentadas allí. ${ }^{4}$ Alguien puede decir, "esta masacre es indicación, aunque sea una excepción, de que la política de masacres estaba dirigida a comunidades insurgentes, no necesariamente a comunidades indígenas". Por lo tanto, argumentaría, la intención de la destrucción no tuvo una motivación racista, ni etnicista, sino política, y esta motivación no está comprendida en la enumeración del tipo de grupos de la definición. Sin embargo, se puede contraargüir que el ejército siguió la misma estrategia diseñada para el área indígena por dos posible razones, porque ésa

4 Manolo Vela, citado arriba, ha hecho una investigación pionera de esta masacre. Pionera no tanto por ser de gente mestiza, sino porque incluye la narración de los perpetradores (Vela Castañeda, 2014). 
era la estrategia a la que estaban acostumbrados los kaibiles o porque en esa zona del Petén hay también comunidades kekchíes. ${ }^{5}$

\section{Definición de genocidio según la Asamblea General de las Naciones Unidas}

Hablemos ahora de la definición de genocidio según las Naciones Unidas. Siempre advierto que no soy un jurista, sino un antropólogo que le brinda material al abogado, a la jueza, a los defensores de derechos humanos, etcétera. Pero, un antropólogo que, al brindar el material, tiene la obligación de iluminarles la realidad según lo que él vislumbra de la ley. Veamos:

\section{Artículo II}

En la presente Convención, se entiende por genocidio cualquiera de los actos mencionados a continuación, perpetrados con la intención de destruir, total o parcialmente, a un grupo nacional, étnico, racial o religioso, como tal

a) Matanza de miembros del grupo;

b) Lesión grave a la integridad física o mental de los miembros del grupo;

c) Sometimiento intencional del grupo a condiciones de existencia que hayan de acarrear su destrucción física, total o parcial;

d) Medidas destinadas a impedir los nacimientos en el seno del grupo;

e) Traslado por fuerza de niños del grupo a otro grupo [Naciones Unidas, 1948]. ${ }^{6}$

La definición se compone de dos partes. La parte de la intención y la de los actos. En esta última he puesto en negrito los dos tipos de actos que caracterizan, como fases temporales, el genocidio guatemalteco, las letras a) y c). La masacre de San Francisco se dio en la primera fase, cuando la población estaba todavía viviendo en sus comunidades y fue sorprendida. Más adelante, tocaré de manera breve la segunda, que me tocó vivir, cuando la población había huido a la montaña y el arma para destruirla fue el hambre y otras condiciones extremas de existencia.
Hay que tener en cuenta que esta definición de genocidio no es exactamente igual a la que contiene el artículo 376 del Código Penal guatemalteco (Código Penal 1973, en Organismo Judicial de Guatemala-Centro Nacional de Análisis y Documentación Judicial, 2017). ${ }^{7}$ Las principales diferencias son que omite el "como tal" de la parte de la intención y que no incluye al grupo racial en la parte de los actos. Sin embargo, como Guatemala reconoce la Convención Internacional, ésta ha pasado a ser ley guatemalteca y cuando la sentencia del juicio de 2013 menciona el Código Penal ella ha de interpretarse a la luz de la Convención. ${ }^{8}$

\section{Tribunal Permanente de los Pueblos (Madrid, 1983)}

Después de haber oído a don Mateo en México fui a presentar su historia a la reunión de la American Anthropological Association (AAA) en Washington, D.C., a fines de 1982. Su tema principal fue la represión que estaba viviendo el pueblo indígena en Guatemala. Estando allí nos encontramos con abogados de Americas Watch, que nos dijeron que probar genocidio era muy difícil debido a las dos palabras que especificaban la intención del mismo, el "como tal". Luego, ya estando de manera permanente en la Ciudad de México, a la espera de que se abriera la posibilidad de entrar desde Chiapas a Guatemala, me invitaron a participar en el Tribunal de los Pueblos en Madrid. Con el material de la masacre de San Francisco de base y con la información muy rica de los periódicos internacionales sobre la represión que se vivía en el país, armé un escrito, tratando de concluir que el gobierno de Guatemala, regido en ese momento por el general Efraín Ríos Montt, había cometido el crimen de genocidio en el sentido estricto de la Convención de Ginebra. ${ }^{9}$

El Tribunal tuvo fuerza moral y política, aunque ninguna jurídica. Sus jueces fueron 16 personalidades de prestigio internacional, premios nobel, juristas internacionales, religiosos comprometidos con la lucha de los pueblos de Centroamérica, como don Sergio Méndez Arceo, obispo de Cuernavaca y otros. Fue organizado

5 Nótese cómo este tipo de casuística, aunque es necesario argüir y contraargüir, nos desvía de la fuerza que nace del centro del relato de don Mateo y de la seriedad del genocidio.

6 Ratificada por Guatemala el 13 de enero de 1950. La Convención entró en vigor el 12 de enero de 1951.

7 Reformado por el artículo 13 del Decreto 20-96, solamente en cuanto a la sanción que ahora es, desde 1996 , de 30 a 50 años de prisión.

8 Tribunal Primero de Sentencia Penal, Narcoactividad y Delitos contra el Ambiente, Sentencia C-01076-2011-00015, 10 de mayo de 2013.

9 El texto del escrito y una somera descripción del Tribunal con los nombres de sus miembros puede consultarse en Falla, 2018b: 149-274. 
en Madrid por el Instituto de Estudios Políticos para América Latina y África (IEPALA), pero a la par de este instituto, sin dar la cara, estaban las organizaciones insurgentes guatemaltecas. Tuvo el patrocinio del entonces alcalde de Madrid, Enrique Tierno Galván, del Partido Socialista Obrero Español (PSOE). Aunque carecía de toda fuerza jurídica, la composición del Tribunal le dio un prestigio incuestionable. El gobierno de Guatemala fue invitado, pero no envió ningún representante para ser parte del tribunal. Obviamente, hubiera sido darle importancia.

La sentencia del Tribunal es extensa, casi 40 páginas, rica en datos históricos y denuncias, pero la condena de genocidio se encuentra en un breve párrafo de la declaración última. ${ }^{10}$ Dice así:

\section{El Tribunal}

DECLARA que las matanzas y el terror desencadenado contra las etnias, con el manifiesto propósito de destruirlas parcialmente, constituye genocidio en el sentido de la Convención Internacional de 1948.

Me concentraré en la argumentación del Tribunal sobre la condena de genocidio. Si nos fijamos palabra por palabra vemos su sentido.

Se refiere a los actos de "matanzas", comprendidos en la letra $a$ ) de la Convención. No se refiere a la letra c) "las condiciones de existencia" extremas, porque en ese momento las masacres resaltaban como el acto más destructivo de la estrategia del ejército, no la persecución de las comunidades enmontañadas a las que les quemaba viviendas, cortaba cosechas y ponía en hambre por lo que murieron incontables niñas y niños.

Pero añade "el terror desencadenado", que yo no mencioné al tratar de la masacre de San Francisco, pero sí al explicar por qué después de ella habían huido cerca de 9000 personas de comunidades vecinas a México movidas por el pánico. Deseaban salvar sus vidas y formaron los campamentos de refugiados de ese extremo noroccidental de la frontera entre Huehuetenango y Chiapas. Pero tampoco en la Convención se habla de terror. Se habla de intención.

El grupo contra el que la destrucción se dirige son "las etnias". Por el texto explicativo, se refiere a los pueblos indígenas identificados por sus idiomas. Los idiomas son una señal de la identidad. No habla del pueblo indígena en general, contrapuesto al no indígena, ni habla de grupo racial.
Habla de intención, pero la palabra que usa es "propósito". Entonces creí que propósito era lo mismo que intención. Pero revisando posteriormente alguna literatura se ve que ya se estaba dando una interpretación más amplia a esa palabra. Ésta era que en "la intención" de la Convención todo lo que se requiere es que "los diversos actos destructivos... tengan un carácter con propósito o un carácter deliberado ( $a$ purposeful or deliberate character) en oposición a un carácter accidental o no intencionado" y que no debe confundirse intención con motivo (Hannum y Hawk, 1989, cit. en Fein, 1993: 20). Este término en la declaración muestra la mano de algún jurista profesional en la redacción. De hecho, había varios, como ya dije. Por ejemplo, Victoria Abellán, catedrática de Derecho Internacional de la Universidad de Barcelona y Richard Baümlin, profesor de Derecho Constitucional en la Universidad de Berna. ${ }^{11}$

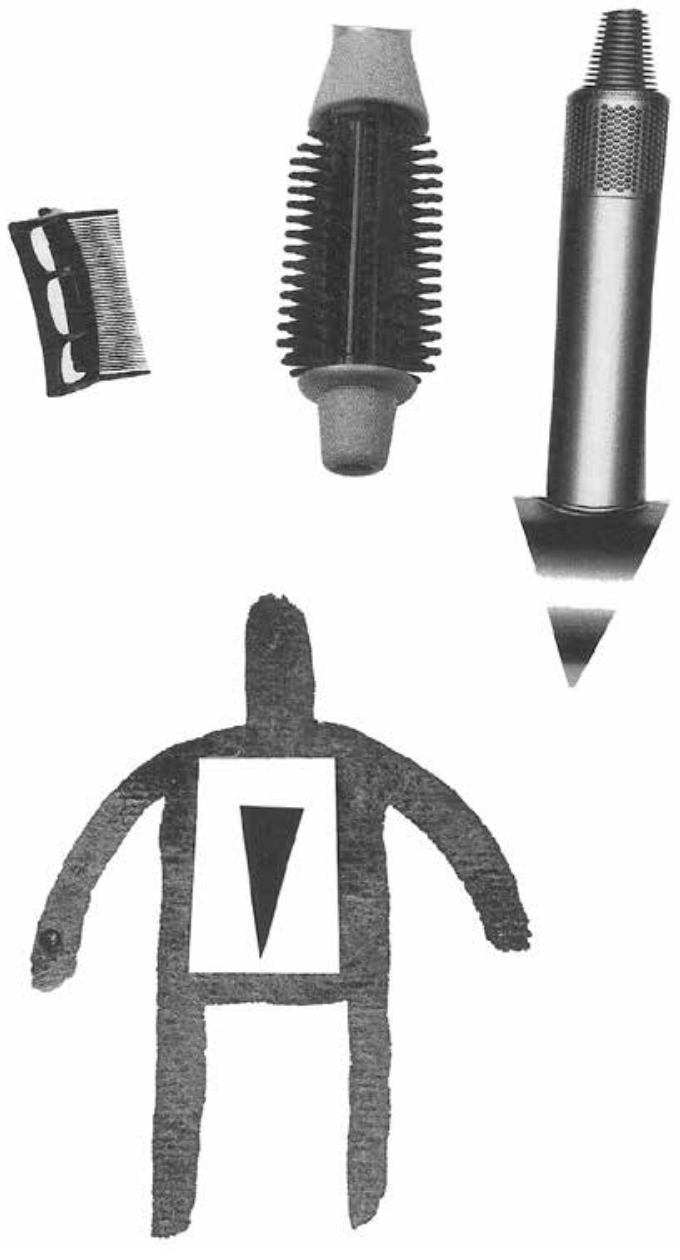

${ }^{10}$ La sentencia del Tribunal Permanente de los Pueblos puede verse en: <www.raco.cat/index.php/RevistaCIDOB/article/ download / 27628/52686>.

${ }^{11}$ La interpretación de la Convención ha ido perdiendo rigidez ante la variedad de genocidios. Dice Helen Fein: "podemos ver que la Convención tiene una flexibilidad mayor que la entendida por algunos” (1993: 20). 
Tampoco considera que el propósito de la destrucción haya sido "total", ni del pueblo ixil, ni de ninguna etnia, ni del pueblo indígena, como era el sentimiento vago, pero muy real de las personas de las comunidades perseguidas, de que el ejército quería "acabar con todos nosotros", esto es, con todo el pueblo indígena o con todo el pueblo de una etnia. Es posible que haya intervenido en el Tribunal la consideración de que ni los capitalistas, ni el ejército podían querer destruir a todo el pueblo indígena, que era la mano de obra para la agroexportación. En fin, difiere de mi propuesta, explicada arriba, acerca de la eliminación total, en intención y en acto, de microunidades étnicas. ${ }^{12}$

\section{La Montaña}

Llegó el día en que logramos entrar de manera clandestina a la selva del Ixcán desde Chiapas (septiembre de 1983). Entonces me olvidé del juicio del genocidio, pero fui a experimentar el genocidio. Una lancha de la iglesia de Ocosingo nos acercó en una noche lluviosa por el río Lacantún hasta donde nos esperaban refugiados guatemaltecos para conducirnos adentro de Guatemala. Estábamos en otro mundo. No sólo por los zancudos, la comida, la lluvia, la falta de casa, la dormida (hamaca bajo toldo), sino porque estábamos en territorio guerrillero. Cuando hablé con don Mateo él trató de no decir nada de la guerrilla, pues por su relación con ella los habían matado. Y cuando estuve en el Tribunal en Madrid tampoco hablé de ella. En el Tribunal se enfocaban las violaciones del ejército, no las acciones guerrilleras. Aquí, en cambio, la guerrilla de carne y hueso estaba presente y la población civil compartía con ella toda el área, aunque se sabía que éramos diferentes. Ante el mundo de fuera y ante el ejército, todos estábamos ocultos en clandestinidad, pero entre nosotros, población civil y guerrilla, no había esa compartimentación. Estábamos forzadamente ocultos porque el ejército había quemado las casas de la población y la había forzado a escapar, o al refugio o a la montaña.

A esa población desplazada fuimos a servir pastoralmente en un equipito de tres personas, entre las que yo llevaba, como arreglo entre mi persona y la guerrilla, la tarea de hacer investigación social. A la guerrilla no le interesaba tanto lo que yo investigara, como que la población recibiera una ayuda espiritual para reforzar la resistencia civil que apoyaba de muchas maneras a la revolución. El interés investigativo lo llevaba yo como un interés personal, porque trataba de comprender cómo había surgido todo el levantamiento campesino de apoyo a la revolución, cosa que no había podido averiguar en el caso de San Francisco.

Estuve cerca de seis meses haciendo de sacerdote acompañante que escuchaba historias en que la presencia guerrillera no se escondía, sino que era parte del levantamiento. Muy distintas del relato de don Mateo en San Francisco. Fui armando así el rompecabezas desde la explotación del campesinado indígena en las costas de Guatemala hasta que se encuentra con la guerrilla en la montaña del Ixcán a principios de los setenta. Fui allí viendo cómo se daba una escalada dialéctica entre las dos fuerzas militares, la guerrilla y el ejército, hasta que el ejército decide acabar con la población civil que apoyaba a la guerrilla por medio de las masacres, algunas de ellas masivas, en 1981 y 1982. Ya mencioné antes las de Cuarto Puebloy Piedras Blancas. El enfoque iba saliendo de las narraciones de la población, combinadas con las de algunos guerrilleros. Era muy distinto del relato de los derechos humanos, puesto que la guerrilla estaba presente continuamente y la acción -no sólo el sufrimiento- de la población también.

A la vez, nos tocó experimentar en carne propia las condiciones extremas de vida del inciso c) del artículo 2 de la Convención; cuando nos perseguían en la montaña, nos hacían pasar hambre, apenas había medicina para los niños, cortaban la cosechay nos metían pavor al sorprendernos desde un bordo con un estallido de metralla. Teníamos que huir en desbandada hasta encontrarnos en un punto de concentración, a veces bajo la lluvia, donde la gente comenzaba a hacer fuego de noche y nos daba de comer caliente. Allí se contaba la gente y se comenzaba a identificar a los que faltaban que se habían quedado tirados o tiradas en la montaña, baleados. Los parientes de las víctimas las buscaban y a los dos o tres días las encontraban. A alguna mujer, recuerdo, la encontraron, pero le faltaba la oreja. Los soldados se la habían cortado como trofeo tal vez para enseñar a los jefes. Tomé muchos apuntes de todo eso que recientemente pudimos publicar. Se me ocurría que haría una trilogía, porque en la cabeza iba armando los volúmenes que escribiría. La trilogía comprendería el levantamiento, las masacres y la resistencia. ${ }^{13}$

\footnotetext{
${ }^{12} \mathrm{Al}$ contrastar la propuesta que llevé con la declaración del Tribunal pude comprobar lo que aceptaron y lo que no. Véase la propuesta y el trabajo etnográfico que la respalda en Falla, 2018b: 149-274.

${ }^{13}$ Hasta hoy se han publicado el levantamiento (Falla, 2015), las masacres (Falla, 2016b) y parte de la resistencia (Falla, 2018a).
} 
Después de la vida en la montaña me encerré en México y escribí los dos primeros volúmenes de la trilogía. Había acordado con el comandante del EGP que no publicaría nada sin que ellos lo vieran antes. Evidentemente, no quería yo dañar el esfuerzo revolucionario, que era débil, con un escrito contraproducente. Después de que él leyó el primero fue muy sincero y me dijo que eso no les servía a ellos y que más bien los dañaría, porque evidenciaba desde dentro la esencia del EGP. No le parecía que junto con la represión del ejército pusiera las acciones guerrilleras, como dije, en dialéctica. Entonces, dejé que durmieran esos tomos y volví a residir en Centroamérica con la intención de regresar después a la montaña. En efecto, en 1987 logré otra vez el acuerdo con la guerrilla y entré de nuevo a la montaña en otro periodo en que la población desplazada ya se había constituido en resistencia y se llamaba a sí misma CPR (Comunidades de Población en Resistencia). Allí estuve hasta 1992, pasando con la población nuevos y más fuertes operativos del ejército. Pero la población estaba mejor organizada y el ejército no logró ni acabarla, ni hacerla huir a México. ${ }^{14}$

En ese tiempo se celebraban los 500 años del "Descubrimiento de América" (la invasión) y un compañero jesuita me urgió que escribiera algo, resumido y directo, del genocidio, pero no con el marco legal de éste. El genocidio era la réplica de la conquista de los españoles. Salí de la montaña y en un mes resumí los dos volúmenes y escribí Masacres de la selva (Falla, 1992). En este libro no suprimí por completo las acciones guerrilleras, pero las dejé en la sombra, destacando las matanzas del ejército. Seguí el criterio del comandante del EGP. A los meses, en diciembre de 1992 tuve que salir de la montaña, pues el ejército encontró mis papeles en un buzón, y desde México volé a Centroamérica a reunirme con el obispo para informarle de lo sucedido. Al pasar por México, el comandante me mandó felicitar por el libro que había tenido mucho impacto en Guatemala.

Sólo quiero recordar que todavía en la montaña yo argüí varias veces con los líderes civiles de las CPR insistiéndoles que debían defender su derecho como población civil para no ser atacados por el ejército, aunque apoyaran, como yo mismo, también civil, a la guerrilla con comida y tareas. Ellos no estaban de acuerdo y algunos que ya salían y daban su testimonio en la ciudad de Guatemala siempre escondían su relación con la guerrilla. Yo les decía que por qué no defendían su derecho. Pero ellos eran realistas. Lo hacían porque por esa relación, aunque fueran población civil con derecho a tenerla, los habían matado.

Meses después, estando ya fuera de la montaña en El Salvador escribí el librito Historia de un gran amor (Falla, 1995). Una metáfora de amor en que yo trataba a las Comunidades de Población en Resistencia como la amada. Antes de ser publicado en castellano les llegó el manuscrito a los líderes civiles y dos de ellos se vinieron a San Salvador con una lista de frases y párrafos que pedían que omitiera, porque aparecía la relación. Lo hice, pero el original en castellano ya se había ido a Holanda, donde se publicó en holandés (flamenco) sin censurar.

Como conclusión de esta experiencia entre la masacre y su denuncia o, lo que es más amplio, entre la investigación social y el juicio, he ido viendo que cada ejercicio tiene su propia dinámica y momento, no se puede preferir uno sobre el otro, pero mi inclinación es por la mirada antropológica y no por la legal, aunque desde la antropología pueda ayudar a la legal y pueda, con temor y temblor, dar opiniones sobre ella.

\section{El juicio de genocidio (2013)}

\section{Hacia el juicio}

Todavía en la montaña, me llegó la noticia de que habían asesinado a Myrna Mack, antropóloga que estaba haciendo investigación junto con Elizabeth Oglesby, ${ }^{15}$ en una zona del área ixil, contigua a las CPR ixil (distinta de las de la selva) (septiembre, 1990). La mataron en la ciudad de Guatemala a cuchilladas. Tal vez ustedes conocen de ella. Es colega. Este crimen hizo que su hermana Helen, junto con un grupo que fundó la Fundación Myrna Mack, se diera a la lucha incansable por condenar en juicio a dos militares, un sargento (1994), que ya fue asesinado, y un coronel (2004), que anda prófugo. Fue el primer paso para romper el muro de la impunidad y caminar hacia el juicio de 2013. Aunque el muro no cayera, había que abrirle un boquete.

Un segundo paso fue la firma de la paz en 1996. Yo estaba todavía en Honduras, pero pude viajar por tierra directamente al Ixcán, a festejarla allí, con las CPR que ya habían salido de la montaña. Al llegar a la frontera, el oficial de migración me pregunta si escribía libros. Yo le contesté que no. Entonces él, viendo mi pasaporte y después levantando la vista, me dijo:

\footnotetext{
${ }^{14}$ Para un análisis concreto de la relación entre genocidio y resistencia en Guatemala véase Falla, 2016a.

${ }^{15}$ Elizabeth Oglesby, perita del juicio de 2013.
} 
“¿Usted no escribió Masacres de la selva?”, “Ah, sî” le dije. Se levantó y me felicitó dándome la mano. Era un estudiante de derecho de una cabecera cercana. Me di cuenta de que el ambiente había cambiado mucho en Guatemala desde los tiempos en que en las fronteras nos agarraban o no nos dejaban pasar.

Como resultado de la firma de la paz se elaboraron dos informes de amplitud nacional sobre la violación de los derechos humanos en Guatemala. El primero, de la Iglesia católica, llamado Recuperación de la Memoria Histórica (Remhi) (Arzobispado de Guatemala, 1998) iniciativa del obispo Juan Gerardi, que fue asesinado a los dos días de la presentación solemne de sus resultados en 1998, y el segundo, de la Comisión para el Esclarecimiento Histórico (CEH, 1999), nacida de los acuerdos de paz. Para ambos, el trabajo de investigación y denuncia sobre el Ixcán, publicado en Masacres de la selva (1992), creo que fue tenido en cuenta.

Estos dos informes, de manera señalada el de la cEH, fueron muy importantes para iniciar las demandas ju-

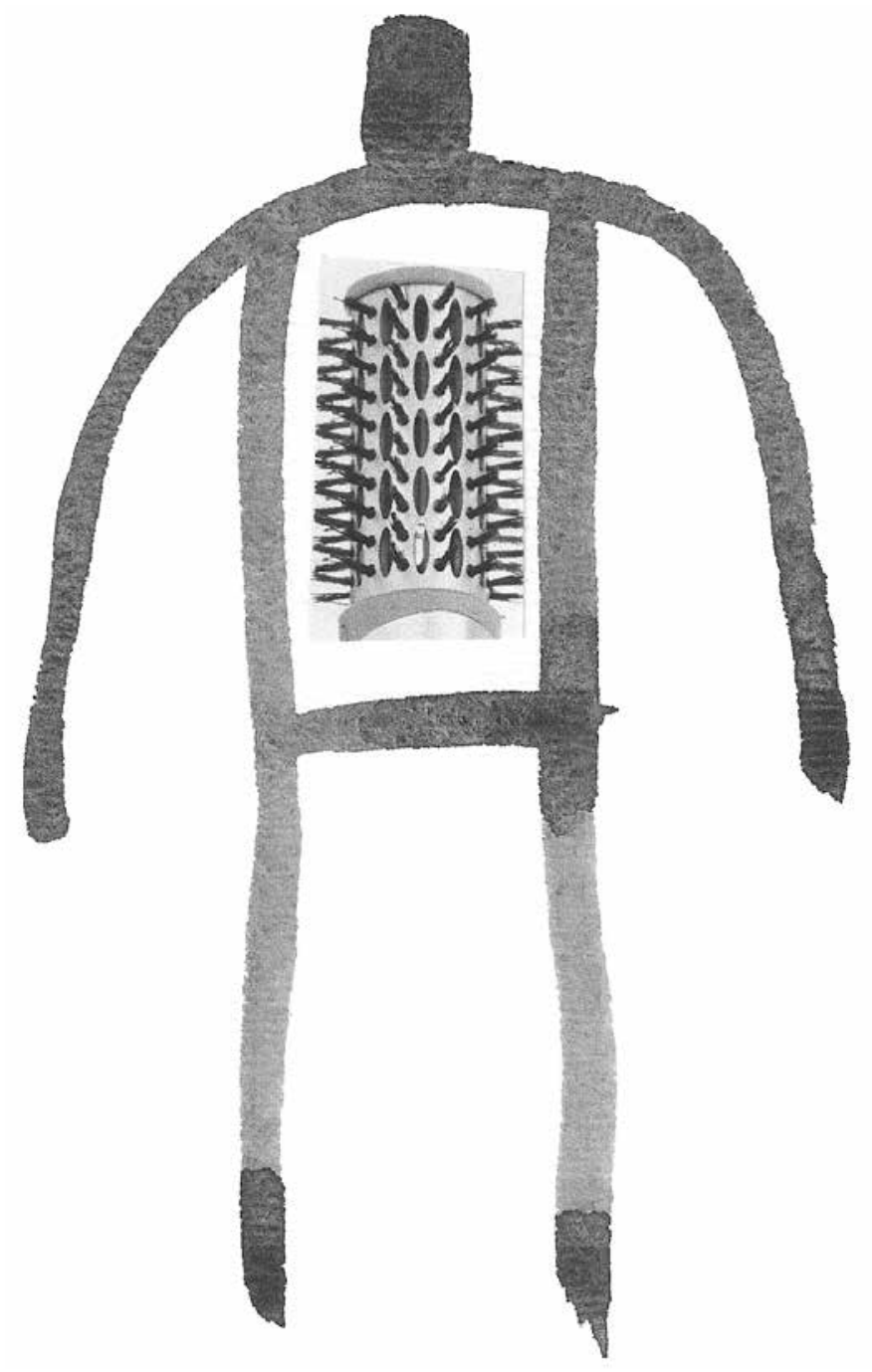

diciales contra los militares de alta jerarquía, especialmente contra Ríos Montt. La CEH había concluido que, durante el conflicto armado interno, 200000 personas habían sido asesinadas, 45000 habían sido desaparecidas con violencia y que un millón habían sido desplazadas. También documentó, como dijimos antes, 626 masacres, y encontró que 400 aldeas habían sido destruidas por las operaciones contrainsurgentes del ejército. Afirmó también que 93 por ciento de las violaciones se debía a las fuerzas del gobierno y que cuatro de cada cinco víctimas eran indígenas mayas. Concluía que el Estado había cometido actos de genocidio contra grupos indígenas mayas en cuatro regiones de Guatemala entre 1981 y 1983 e indicaba que el periodo de la máxima violencia había ocurrido durante el régimen de Ríos Montt, de marzo de 1982 a agosto de 1983. Sin embargo, el objetivo de ese informe no era señalar a ningún individuo como responsable.

Un tercer paso fue la denuncia que puso Rigoberta Menchú, Premio Nobel, contra Ríos Montt y otros militares en 1999 ante la Audiencia Nacional de España. Más adelante, estando ya en Guatemala, esta denuncia me implicaría como perito.

Un cuarto fue cuando en 2001 la Asociación por la Justicia y la Reconciliación (AJR), en representación de 22 comunidades de cinco regiones afectadas por la violencia gubernamental, y el Centro para la Acción Legal en Derechos Humanos (CALDH) acusaron a Ríos Montt y otros miembros del alto mando guatemalteco del crimen de genocidio ante el Ministerio Público (MP).

Hasta 2011 había estado yo en Honduras, distanciado de todos estos pasos hacia el juicio, pero en 2008 la Fundación Rigoberta Menchú me invitó a viajar a Madrid junto con muchos otros testigos a declarar ante la Audiencia. Este proceso estuvo dormido desde 1999 hasta que la Audiencia Nacional pidió la extradición a España de Ríos Montt, basada en la jurisdicción universal en 2005.

Eso haría que luego me enganchara de nuevo en 2008, aunque independientemente de la dinámica de CALDH, a investigar el caso de San Francisco, del que conocía cómo fue la masacre, pero no los antecedentes históricos, ni el desarrollo posmasacre hasta ese momento (2010). Estando con los sobrevivientes, tuve la oportunidad de constatar en profundidad el trabajo fino del CALDH con las bases para preparar el juicio contra Ríos Montt y otros generales, que todavía se veía incierto, en la comunidad chuj de Yulaurel. Yo no vi cómo trabajó el CALDH en la zona ixil, pero conocí con mucho detalle su documentación fresca en esa otra área: cómo definía al grupo de testigos en la aldea y cómo se organizaban los talleres y reuniones de información con ellos. Todo esto llevaba consigo un paciente 
trabajo de investigación, la preparación de los testigos para la primera audiencia que tendrían ante el MP y el apoyo del acompañamiento internacional, como protección a los testigos y a la comunidad. Pude seguir las huellas del trabajo del CALDH en la comunidad chuj de Yulaurel, emparentada estrechamente con la de San Francisco, que había sido arrasada del mapa. A la vez, el CALDH llevaba el intrincado proceso judicial que parecía que nunca llegaría a ganar. ${ }^{16}$

El CALDH estaba entonces trabajando de la misma forma en cuatro comunidades del área ixil, Xix e Ilom en Chajul, para el periodo del presidente Lucas García, y San Francisco Javier y Vivitz, en Nebaj, para el periodo de Ríos Montt. Este arranque desde la base le dio al juicio una peculiaridad especial: se enraizaba en la población para darle fuerza al juicio, como hecho social. Creo que esta relación con la base no ha sido suficientemente visibilizada.

No sé en qué momento el CALDH y la AJR decidieron angostar su foco. Fue una decisión práctica y sabia, aunque pudo tener sus inconvenientes. En vez de cubrir las principales áreas lingüísticas indígenas del país (kiché, chuj, kanjobal, ixil...), como habían hecho al comenzar, se centraron en una sola etnia, la ixil, donde el genocidio había sido muy intenso, y se contaba con mucha información. Además, había testigas y testigos dispuestos a declarar. Era una ventaja práctica, porque en términos geográficos se reducía el área.

Por otro lado, desde un punto de vista estratégico se escogía sólo una etnia, cuya señal principal era la lengua ixil, para apuntar a la intencionalidad del Estado de destruirla. No sé si al tomar esa decisión se previó la enorme riqueza de la declaración de las mujeres, desgarradas por la experiencia de la violación sexual, que luego pasarían por un proceso de empoderamiento realmente notable, y que hizo estremecer al mundo con sus declaraciones.

El 14 de enero de 2012 por fin cayó la barrera que detenía el juicio, cuando Ríos Montt perdió la inmunidad como diputado del Congreso de la República. El CALDH y la AJR se dieron prisa, entonces, para sentarlo en el banquillo de los acusados.

\section{El juicio 19 de marzo-10 de mayo de 2013}

Yo no estuve presente en el juicio. Tuve que viajar a Panamá a una evaluación con lo ngobes. Lo seguí, lo que podía, por radio y por las noticias. Pero antes de partir dejé para publicación en el medio digital Plaza Pública un artículo que venía trabajando: “Cómo que no hubo genocidio?” (Falla, 2013). Su argumentación, más pulida, era la misma que presenté al Tribunal de los Pueblos.

Cito a Juan Hernández-Pico para resumir el juicio. Él es jesuita y compañero, directivo de la Fundación Myrna Mack. En ese entonces escribía mensualmente sobre Guatemala para la revista nicaragüense Envío. Su artículo es muy amplio y preciso. Toca la parte legal y la dinámica social y política del juicio. También explica la nulidad decretada a los diez días por la Corte de Constitucionalidad.

El 10 de mayo el Tribunal Primero A de Mayor Riesgo (Penal, Narcoactividad y Delitos contra el Ambiente), presidido por la Juez Jazmín Barrios, sentenció al General en retiro José Efraín Ríos Montt a 50 años de prisión inconmutable por la matanza, durante su periodo de Jefe de Estado (198283), de 1771 indígenas ixiles, calificada como genocidio; y a otros 30 años de prisión igualmente inconmutable por "delitos contra deberes de la humanidad", lo que en la formulación internacional conocemos como "crímenes de lesa humanidad": tortura, desaparición forzada y otros delitos, que son imprescriptibles según el derecho interno guatemalteco y los tratados internacionales suscritos por Guatemala (Decreto 145 / 1996, Ley de Reconciliación Nacional). El Tribunal absolvió, por duda razonable de su culpabilidad, al general retirado Mauricio Rodríguez Sánchez, que en el mismo período era Jefe de Inteligencia del Ejército (Hernández-Pico 2013). ${ }^{17}$

Quisiera poder comentar el juicio por su importancia nacional. Conozco la sentencia, ${ }^{18}$ aunque no la he estudiado, y conozco el hecho social, pero no tengo el conocimiento suficiente de él. No voy a entrar en él. Se pueden consultar las fuentes citadas.

Existe un material muy abundante que merece un estudio riguroso tanto de la sentencia mencionada, escrita de 718 páginas, como de los audios. ${ }^{19}$ En los audios se encuentran los peritajes y los testimonios. Tanto los peritajes como los testimonios sólo están resumidos en la sentencia. En los testimonios se encuentran las voces de las personas que interrogan a los testigos, las voces de los traductores y las de las testigas y testigos en ixil $u$ otro idioma. Hay una riqueza inmensa que supera a la sentencia esque-

16 Véase Negreaba de zopilotes (Falla, 201 1: 243-274).

17 Véase también (Burt, 2016).

18 Tribunal Primero de Sentencia Penal, Narcoactividad y Delitos contra el Ambiente, Sentencia C-01076-201 1-00015, 10 de mayo de 2013.

19 “Audios juicio por genocidio", en Plaza Pública <http: / /www.plazapublica.com.gt/audiosespecial/juicio-por-genocidio>. 
matizada y redactada a marchas forzadas. Es tiempo de hacer un estudio a fondo del juicio, superando la polarización. No se trata ya de ver si hubo o no genocidio, sino de encontrar las riquezas y limitaciones del juicio, como hecho legal y social. Las riquezas superan por mucho a las limitaciones. No hay que temer ser profundamente crítico. Cuando se es, reluce la verdad con más claridad. ${ }^{20}$

\section{Conclusiones}

\section{Ciencias sociales o derecho}

Dice el masacrólogo francés, Jacques Sémelin, que "es indispensable que las investigaciones sobre el genocidio se emancipen del derecho para conquistar su propia madurez en el campo de las ciencias sociales" (Sémelin, 2005: 367). Por mi exposición se habrá visto que durante muchos años me he estado moviendo entre la antropología y la denuncia del genocidio, entre la escucha del testimonio y el intento de encajonarlo en la definición legal, entre la pasión intelectual por buscar el origen social de las grandes masacres y el enojo para denunciarlas con la finalidad de que paren y nunca más se den. ¿Qué sacar de este ir y venir? Ciertamente, mi experiencia es que el marco legal limita la imaginación y la creatividad para buscar de dónde provino todo esto. Pero ese marco, construido desde la experiencia universal, con la ayuda de las ciencias sociales también, ayuda a profundizar el alcance amplísimo de la masacre concreta, que no sólo tuvo el propósito de destruir un pueblo de Guatemala, sino al género humano, aspecto que me parece que en el calor del juicio particular de 2013 quedó oscurecido.

\section{Pasión o acción}

La tendencia del juicio es a resaltar la pasividad de las víctimas, lo que han sufrido inocentemente, y subrayar la actividad del agresor y su inmensa imaginación para la crueldad. Esta tendencia se magnifica si existe la percepción generalizada, a veces religiosamente influida (Semana Santa), de que las víctimas mientras más pasivas más inocentes, a lo que hay que agregar el hecho de que las víctimas temen que al presentar su lado activo todavía pueden ser dañadas. Por lo que hicieron, el agresor las incluyó como enemigo interno, aunque eran población civil. La sentencia del juicio de 2013, que es sólo una parte del juicio, es una triste lista de masacres, violaciones, torturas, quemas de aldeas... como si las víctimas no hubieran participado, en mayor o menor grado, más o menos conscientes del alcance de su participación y más o menos responsables de sus errores, en una lucha de liberación innegablemente positiva, aunque utópica y trágicamente fracasada (por el momento). Por el contrario, eso sí, el juicio con la denuncia empoderada por parte de las víctimas fue un hecho activo que estremeció la estructura nacional, no sólo a responsables militares de las violaciones, sino a las clases ricas y al mismo presidente del país, Otto Pérez Molina. El grito y llanto de las mujeres violadas, que se puede volver a escuchar en los audios, no fue únicamente un gemido de humillación, sino una protesta cimentada en la inocencia de sus acciones, aunque no las develaran todas. La riqueza del juicio espera, me parece, que se complete el contenido doloroso con el lado subversivo de esa misma población que colaboró con la insurgencia. De ambos aspectos arranca la fuerza para la memoria y la emancipación. Esta tarea, como somos limitados y nadie puede hacer todo a la vez, es más propia de las ciencias sociales que del derecho. Pero el uno apuntala a las otras.

\section{El virus del genocidio}

Tanto las ciencias sociales como el derecho intentan prevenir, controlar y castigar la reproducción del genocidio en el mundo entero. Un esfuerzo global contra sus raíces que están, como todos sabemos, en el racismo, el desprecio a la mujer, la discriminación a los pueblos indígenas, el sentimiento de la superioridad religiosa, la dominación de las naciones y, englobando todas, la cerrazón de los individuos y los pueblos frente al otro (otra). Pero, como sucede con la pandemia, el personal más expuesto es el que está luchando cuerpo a cuerpo contra el virus. Así, los que hemos estado luchando de cerca contra el genocidio, podemos fácilmente contagiarnos al ver al agresor, como una máquina de hacer el mal o como un animal con una crueldad casi innata. Piénsese en la caricatura de Ríos

\footnotetext{
${ }^{20}$ El juicio de genocidio anulado volvió a iniciarse el 16 de marzo de 2016 y finalizó el 26 de septiembre de 2018 . Confirmó que el ejército nacional cometió genocidio en contra del pueblo ixil, pero no condenó a nadie. Ríos Montt ya había fallecido y Rodríguez Sánchez fue absuelto nuevamente. En octubre de 2019 se inició un nuevo proceso penal en contra de tres miembros de la cúpula militar del periodo de Romeo Lucas García (1978-1982). Están acusados de genocidio y delitos contra los deberes de humanidad en contra del pueblo maya ixil de Guatemala. Las audiencias de la etapa intermedia iniciaron el 9 de marzo de 2020, pero días después comenzó el confinamiento por la pandemia (Impunity Watch, 2020).
} 
Montt, como fiera con sangre en los colmillos. Difícil no hacerlo después de oír tantos y tantos crímenes contra víctimas inocentes, cometidos al frente de su gobierno. Y difícil no estigmatizar, junto con él, a sus defensores, a su ejército de entonces y de ahora, e incluso a sus amigos y familiares. Pero de la esencia del género humano es la diferencia. Al negar, entonces, el derecho a esa diferencia, en teoría o en la práctica, sutilmente, como virus invisible, puede el monstruoso genocidio estar entrando, sin darnos cuenta, en nuestros esfuerzos y luchas. Las polarizaciones que seguimos viviendo son un caldo de cultivo fácil de este contagio.

\section{Genocidio y espiritualidad}

En un escrito post mortem, dice Lemki que las razones espirituales de la Convención son la compasión humana y la defensa de "los recursos espirituales de la humanidad". ${ }^{21}$ Tal vez yo iría un poco más allá al buscar la relación entre genocidio y espiritualidad partiendo de la noche oscura de don Mateo. Con la masacre se le quitaron objetos y personas, pues le quemaron casas y asesinaron a todos sus familiares, pero algo adicional, se le quitó el sentido de la vida, recordemos su expresión de andar como bolo. “¿Por qué? ¿Por qué pasó todo eso?” En este grito interior se cifra la experiencia de la noche oscura, que en otra parte he llamado la experiencia de la nada (Popol Vuh) ${ }^{22}$ Una experiencia fundante de espiritualidad muy fuerte. Porque al intentar destruir toda la humanidad, el genocidio no sólo destruye pueblos, culturas y espiritualidades (eso lo enfatiza Lemkin), sino que genera en el pueblo que sobrevive esta experiencia agudísima de noche de donde sale la luz de la esperanza, porque don Mateo está vivo. Tal vez él no lo explicita y tarda en asumir su nueva situación. Pero desde ese horizonte, como una luminosidad no objetivada, va a entender todas las cosas. Entonces, estos pueblos que han sido víctimas del genocidio, pero que siguen viviendo, tienen esta capacidad espiritual de cara al mundo que los contempla. El pueblo maya de Guatemala, en este caso, me parece que es más comunicador de conciencia y fuerza transformadora por el genocidio padecido y sobrevivido, que por todas las gloriosas pirámides del pasado.

\section{Fuentes}

Arzobispado de Guatemala

1998 Guatemala: Nunca más, Oficina de Derechos Humanos del Arzobispado de Guatemala. Proyecto Interdiocesano la Recuperación de la Memoria Histórica (Remhi), 4 vols.

Burt, Jo-MARIE

2016 "From heaven to hell in ten days: the genocide trial in Guatemala", en Journal of Genocide Research, vol. 18, núm. 2-3, pp. 143-169.

COMISIÓN PARA

El Esclarecimiento Histórico

1999 Guatemala, memoria del silencio. Conclusiones y recomendaciones del Informe de la $\mathrm{CEH}$, Comisión para el Esclarecimiento Histórico, Guatemala.

FALla, RicARDO

1983 "Masacre de la finca San Francisco, Huehuetenango, Guatemala. 17 de julio de 1982", en ECA, Estudios Centroamericanos, núm. 417 418, julio- agosto, pp. 641-662.

FALLA, RicARDO

1992 Masacres de la selva, Editorial Universitaria, Guatemala.

FALLA, RicARDO

1995 Historia de un gran amor, Ediciones San Pablo, Guatemala [también en Editorial Universitaria, 2015].

FALla, RicARDO

2011 Negreaba de zopilotes. Masacre y sobrevivencia. Finca San Francisco, Nentón, Guatemala (1871-2010), Asociación para el Avance de las Ciencias Sociales en Guatemala, Guatemala.

FALla, RicARdo

2013 “Cómo que no hubo genocidio?”, en Plaza Pública, 19 de marzo <https://www.plaza publica.com.gt/content/como-que-no-hubo-

FALLA, RicARDO genocidio $>$ [ 10 de noviembre de 2021].

2015 Ixcán. El campesino indígena se levanta. Guatemala (1966-1982), Universidad Rafael Landívar/Asociación para el Avance de las Ciencias Sociales en Guatemala / Editorial Universitaria (Serie $\mathrm{Al}$ atardecer de la vida... Escritos de Ricardo Falla, 3) Guatemala.

FALLA, RicARDO

2016a "Genocidio y resistencia", contribución a la Primera Conferencia Internacional sobre Genocidio y Resistencia en Guatemala, organizada por USC Shoah Foundation y el Center for Advanced Genocide Research, Los ÁngeFALLA, RicARDO les, California, 14 de septiembre.

2016b Ixcán. Masacres y sobrevivencia. Guatemala 1982, Universidad Rafael Landívar/Asociación para el Avance de las Ciencias Sociales en Guatemala / Editorial Universitaria (Serie Al atardecer de la vida... Escritos de Ricardo Falla, 4), Guatemala.

21 "La filosofía de la Convención contra el Genocidio se basa en la fórmula del cosmos humano. Este cosmos consiste de cuatro grupos básicos: el nacional, el racial, el religioso y el étnico. Los grupos están protegidos no sólo por razones de compasión humana, sino también para prevenir que se drenen los recursos espirituales de la humanidad" (Fein, 1993:

11 ; cursivas mías).

${ }^{22}$ Véase (Falla, 2019). 
FALLA, RicARDo

2018a Ixcán. Pastoral de acompañamiento en área de guerra. Guatemala 1981-1987, Universidad Rafael Landívar / Asociación para el Avance de las Ciencias Sociales en Guatemala/Editorial Universitaria (Serie Al atardecer de la vida... FALLA, RicARDo Escritos de Ricardo Falla, 5), Guatemala.

2018b Las lógicas del genocidio guatemalteco: una mirada etnográfica desde la fe y la revolución. Febrero de 1982 a agosto de 1983, Universidad Rafael Landívar / Asociación para el Avance de las Ciencias Sociales en Guatemala/ Editorial Universitaria (Serie $\mathrm{Al}$ atardecer de la vida... Escritos de Ricardo Falla, 6), Guatemala.

FALLA, RicARDO

2019 "Religiosidad y espiritualidad", intervención en el XIII Congreso de Estudios Mayas, 3 a 6 de julio, Universidad Rafael Landívar, Guatemala.

Fein, Helen

1993 Genocide: A Sociological Perspective, Sage, Londres [publicado en 1990 en Current Sociology, vol. 38, núm. 1, primavera, pp. 1-126].

HANNUM, HuRst

\section{Y DAVID HaWK}

1986 The Case Against the Standing Committee of the Communist Party of Kampuchea, Nueva York, Cambodia Documentation Commission.
Hernández-Pico, JuAn

2013 "El juicio contra Ríos Montt: un hito históriIMPUNITY WATCH co", en Revista Envío, núm. 376, julio.

2020 "Caso de genocidio contra el Pueblo Ixil durante la dictadura militar de Lucas García”, en Impunity Watch, 12 de marzo <https: / /www. impunitywatch.nl/docs / Factsheet_Caso Genocidio_Ixil-_March2020-spanish.pdff $>[1 \overline{0}$ de noviembre de 2021 ].

\section{NACIONES UNIDAS}

1948 Convención para la Prevención y la Sanción del Delito de Genocidio, Asamblea General, Resolución 260 A (III) del 9 de diciembre.

Organismo Judicial de Guatemala-

Centro Nacional de Análisis

Y DOCUMENTACIÓN JUdicial

2017 "Decreto número 17-73. Código Penal", en Compilación de Leyes Penales de Guatemala. Actualizada hasta el 28 de febrero de 2017 , Organismo Judicial de Guatemala-Centro Nacional de Análisis y Documentación Judicial, Guatemala, pp. 1-84.

\section{SÉmelin, Jacgues}

2005 Purifier et Détruire. Usages politiques de massacres et génocides, Seuil, París.

Vela Castañeda, Manolo E.

2014 Los pelotones de la muerte. La construcción de los perpetradores del genocidio guatemalteco, Colegio de México, México. 